\title{
The new course of FITs mechanism for PV systems in Italy: novelties, strong points and criticalities
}

\author{
Salvatore Favuzza, Gaetano Zizzo* \\ Dipartimento di Ingegneria Elettrica, Elettronica e delle Telecomunicazioni - Università di Palermo Palermo, \\ Italy \\ *Corresponding author. Tel: +39 0916615205, Fax: +39 091488452, E-mail: zizzo@dieet.unipa.it
}

\begin{abstract}
The paper deals with the new course of the Feed-in Tariffs mechanism for photovoltaic systems that will start from January 1, 2011 in Italy with the actuation of the Government Decree DM 06/08/2010. After a short introduction on Feed-in Tariffs and Net-metering in Italy, the paper focuses the attention on an economical comparison between the incentives established by the Government Decree DM 19/02/07, ended on December 31,2010 and those introduced by the DM 06/08/2010. The economical comparison is based on three indexes: the Pay Back Period, the Net Present Value and the Internal Rate of Return, characterizing the investments done for the realization of the photovoltaic systems. In particular, simulations show how the new Decree significantly penalizes the architectural integration, that represents a strongly criticism of the new incentive policy.
\end{abstract}

Keywords: Renewable Energy Resources, PV systems, Feed-in Tariffs, PBP, NPV, IRR

\section{Nomenclature}

F $\quad$ FIT value $€ / k W h$

$c_{\mathrm{kWh}, \mathrm{t}}$ the electricity price at the $t^{\text {th }}$ year ... $€ / \mathrm{kWh}$

$u$ percentage of maintenance cost............\%

$C_{0} \quad$ initial investment cost.............................. $€$

$C_{\text {add }}$ yearly insurance cost .............................. $€$

i Weighted Average Cost of Capital

(WACC).
$N \quad$ lifetime of the investment ................... year

NPV Net Present Value ....................................

IRR Internal Rate of Return ......................... \%

PBP Pay Back Period................................ year

$E_{t} \quad$ Energy produced at the $t^{\text {th }}$ year ......... kWh

\section{Introduction}

In 2001 [1], the EU has officially recognized the need of promoting Renewable Energy Sources (RES) as a priority measure since their exploitation contributes to environmental protection and sustainable development and makes it possible to meet Kyoto [2] targets more quickly. The latest evidence of the diligence of the European countries in promoting the use of RES is the European Council Directive 2009/28/EC [3], targeting an objective of $20 \%$ as contribution of the RES on the total European energetic consumption in 2020. Such a bond represents, without doubts, a challenging goal, that will be able to be reached only with an effective RES incentive policy and with a concrete effort towards the improvement of the energetic efficiency of these sources.

Photovoltaic (PV) had a higher grow rate in the last decade with respect to the other RESbased systems. The data reported by Nomisma Energia [4] show how, among all the RESbased technologies, PV expected to contribute a major share of renewable energies in the coming decades.

PV technology is still very expensive and its development is strongly connected to incentive policies promoted by national governments and encouraged by the EU, which is striving to ensure the PV industry remains competitive on the worldwide market.

The most common incentive mechanism in Europe, adopted by 15 countries, is represented by Feed-in Tariffs (FITs) [5]. It involves the obligation on the part of an electric utility to 
purchase electricity generated by renewable energy producers in its service area paying a tariff determined by Public Authorities and guaranteed for a specific time period.

In Italy FITs mechanism has been introduced in 2005 with a Government Decree [6] and has been changed during the years through another Government Decree in 2007 [7] and arriving today, with the Decree of the Ministry of the Economical Development 06/08/2010 [8], at its third version.

The purpose of this work is to highlight the novelties of the last Decree, and the differences with the previous one and to examine the effects of this new course on the diffusion of photovoltaic in Italy.

\section{Feed-in Tariffs in Italy}

FITs mechanism obligates an utility to purchase electricity generated by PV systems in its service area, paying a tariff determined by the public authorities and guaranteed for a specific time period. The value of a FIT represents the full price received by an independent producer for any $\mathrm{kWh}$ of electric energy produced by a PV system.

Different tariffs are defined for different countries, depending on resource conditions and socio-political situation. In Italy, since 2005 va rious Government Decrees have defined a support system that allows the producers to have recourse contemporary to FIT and Netmetering for PV installations with rated power not over $200 \mathrm{kWp}[6,7,8]$.

Net-metering is a support strategy that allows the customers to offset their electricity consumption with small-scale RES over an entire billing period using it at a different time than it is produced, without considering when the power is consumed or generated and storing their energy in the Utility's grid. With Net-metering the energy produced and injected in the grid has the same economical value of the energy sold by the Utility to the customers.

Over $200 \mathrm{kWp}$, the customer could choose if selling the whole electric energy produced by the PV system to the local Utility or if using part of this energy for its own consumptions.

In this case the support system is composed by two terms:

- a FIT for the whole electricity produced by the PV system;

- a value for the electricity produced by the PV system which can be used for the own consumption (with a saving in the electricity cost) or partially or totally sold to the local Utility at a price established by the Italian Authority for Electric Energy and Gas.

Therefore, while in the other countries the FIT is paid only for the energy effectively sold to the Utility, in Italy, for 20 years, the producer receives a FIT for the whole produced electric energy and a payment for the part of electric energy sold to the Utility.

A new Decree of the Ministry for Economical Development in 2007 (DM 19/03/2007) simplified the procedure to obtain the incentive and changed the FITs values distinguishing among Field installed or not integrated in building, Partially Integrated in Building and Building Integrated PV Systems [7].

Today, thanks to the success and to the experience done with the DM 19/03/2007, the Italian Government has emitted the DM 06/08/2010, that replaces the previous one, introducing new rules and new tariffs for PV systems in Italy starting from January 1, 2011 [8]. 
The main differences introduced by the new Decree deal with the classification of the PV systems and the values of the related FITs. The new classification is the following:

- $\quad$ in buildings PV systems;

- $\quad$ building integrated PV systems with innovative characteristics;

- $\quad$ concentration PV systems (CPV);

- $\quad$ PV systems with technological innovation;

- other PV systems.

The characteristics of the PV systems with technological innovation and the related FITs will be established with a further Decree.

Tables 1 and 2 report the FITs values, respectively, for building integrated PV systems with innovative characteristics and for CPV (categories not contemplated by the previous Decree).

Table 1. FITs in DM 06/08/2010 for PV systems integrated with innovative features.

\begin{tabular}{cc}
\hline Rated power range $(\mathrm{kW})$ & FIT $(€ / \mathrm{kWh})$ \\
\hline $1 \leq \mathrm{P} \leq 20$ & 0.440 \\
$20<\mathrm{P} \leq 200$ & 0.400 \\
$20<\mathrm{P} \leq 5000$ & 0.370 \\
\hline
\end{tabular}

Table 2. FITs in DM 06/08/2010 for PV concentration systems.

\begin{tabular}{cc}
\hline Rated power range $(\mathrm{kW})$ & FIT $(€ / \mathrm{kWh})$ \\
\hline $1 \leq \mathrm{P} \leq 200$ & 0.370 \\
$200<\mathrm{P} \leq 1000$ & 0.320 \\
$1000<\mathrm{P} \leq 5000$ & 0.280 \\
\hline
\end{tabular}

Table 3 reports the values of the FITs stated by the 2007 and by the 2010 Decrees in the period may-august 2011.

Table 3. FITs in DM 19/02/07 and DM 06/08/10.

\begin{tabular}{cccccc}
\hline \multirow{2}{*}{$\begin{array}{c}\text { Rated power } \\
\text { range }(\mathrm{kW})\end{array}$} & $\begin{array}{c}\text { Not } \\
\text { integrated } \\
(€ / \mathrm{kWh})\end{array}$ & $\begin{array}{c}\text { Partially } \\
\text { Integrated } \\
(€ / \mathrm{kWh})\end{array}$ & $\begin{array}{c}\text { Totally } \\
\text { Integrated } \\
(€ / \mathrm{kWh})\end{array}$ & $\begin{array}{c}\text { PV in } \\
\text { buildings } \\
(€ / \mathrm{kWh})\end{array}$ & $\begin{array}{c}\text { Other PVs } \\
(€ / \mathrm{kWh})\end{array}$ \\
\hline $1 \leq \mathrm{P} \leq 3$ & 0.384 & 0.422 & 0.470 & 0.391 & 0.347 \\
$3<\mathrm{P} \leq 20$ & 0.364 & 0.404 & 0.442 & 0.360 & 0.322 \\
$20<\mathrm{P} \leq 200$ & 0.346 & 0.384 & 0.422 & 0.341 & 0.309 \\
$200<\mathrm{P} \leq 1000$ & 0.346 & 0.384 & 0.422 & 0.335 & 0.303 \\
$1000<\mathrm{P} \leq 5000$ & 0.346 & 0.384 & 0.422 & 0.327 & 0.289 \\
$\mathrm{P}>5000$ & 0.346 & 0.384 & 0.422 & 0.311 & 0.275 \\
\hline
\end{tabular}

PV systems are considered in the category "PV systems in buildings" if they are installed according with particular modalities proposed by the DM 06/08/10; if the PV systems do not fulfill these modalities, they must be included in the category "Other PV systems".

With reference to the previous classification, inside the category "PV in buildings" are, therefore, included some totally integrated PV systems and almost the totality of the partially integrated PV systems; in the category "other PVs" are included field PV systems, not 
integrated PV systems and some of the partially integrated PV systems.

Only with reference to the PV systems typologies of the previous classification and belonging to the new ones, in Table 4 the FITs percentage variation between the old and the new decree are reported.

Table 4. FITs percentage variations.

\begin{tabular}{ccccc}
\hline $\begin{array}{c}\text { Rated power } \\
\text { range } \\
(\mathrm{kW})\end{array}$ & $\begin{array}{c}\text { Not integrated } \\
(\text { other PVs }) \\
(\%)\end{array}$ & $\begin{array}{c}\text { Partially } \\
\text { Integrated } \\
(\text { other PVs }) \\
(\%)\end{array}$ & $\begin{array}{c}\text { Partially } \\
\text { Integrated } \\
(\mathrm{PV} \text { in buildings })\end{array}$ & $\begin{array}{c}\text { Totally Integrated } \\
(\mathrm{PV} \text { in buildings })\end{array}$ \\
\hline $1 \leq \mathrm{P} \leq 3$ & -9.64 & -17.77 & -7.35 & -16.81 \\
$3<\mathrm{P} \leq 20$ & -11.54 & -20.30 & -10.89 & -18.55 \\
$20<\mathrm{P} \leq 200$ & -10.69 & -19.53 & -11.20 & -19.19 \\
$200<\mathrm{P} \leq 1000$ & -12.43 & -21.09 & -12.76 & -20.62 \\
$1000<\mathrm{P} \leq 5000$ & -16.47 & -24.74 & -14.84 & -22.51 \\
$\mathrm{P}>5000$ & -20.52 & -28.39 & -19.01 & -26.30 \\
\hline
\end{tabular}

The analysis of the percentage variations puts into evidence that the new FITs mainly penalize totally integrated PV systems with respect to the not integrated ones.

\section{Methodology}

In the following the previous Decree and the new one are compared, simulating different characteristics of the sample PV systems, in order to explore the possible situations in which the two Decrees give place to different values of the economical indexes.

The economical analysis is performed by calculating, the cash flow, the PBP, the NPV and the IRR of the investment done for realizing the PV systems.

The cash flows depend on several factors such as the equivalent hours produced, the FITs value, the gain for the avoided bill cost, the maintenance and management costs, etc.

All these factors can be translated into cash flows $\mathrm{C}_{t}{ }^{*}$ by means of the following equation obtained by adding algebraically all the costs $C_{i}$ and all the profits $P_{i}$ related to the generic $i^{\text {th }}$ year:

$C_{t}^{*}=\sum_{i} P_{i, t}-\sum_{i} C_{i, t}=F \cdot E_{t}+c_{k W h, t} \cdot E_{t}-u \cdot C_{0}-C_{a d d}$

In order to carry out a realistic analysis, the cash flows are annualized using the classical expression according to [9]:

$C_{t}=\frac{C_{t}^{*}}{(1+i)^{t}}$

Equation (2) allows to obtain the equivalent present value of the cash flow of the $\mathrm{t}^{\text {th }}$ year, knowing its nominal value ${ }^{1}$.

For example, in the case of $\mathrm{i}=5 \%$, a cash flow $C_{t}{ }^{*}=1000 €$ produced at the $10^{\text {th }}$ year is equivalent to $614 €$ at year 0 
The NPV and the IRR indices are defined by the following expressions [9]:

$$
N P V=\sum_{t=1}^{N} \frac{C_{t}^{*}}{(1+i)^{t}}-C_{0} \quad ; \quad C_{0}-\sum_{t=1}^{N} \frac{C_{t}}{(1+I R R)^{t}}=0
$$

\section{Results}

General data:

Yearly reduction of the photovoltaic production: $1 \%$; Electricity price at year $0: 0.15 € / \mathrm{kWh}$;

Coefficient evaluating the maintenance and management cost: 1\%; WACC: $3 \%$

First case: $10 \mathrm{~kW}$ PV system

Classification according to DM 19/02/07: Not integrated - FIT Value: $0.364 € / \mathrm{kWh}$

Classification according to DM 06/08/10: Other PVs - FIT Value: $0.322 € / \mathrm{kWh}$

Initial investment cost: $45000 €$ - Yearly production at year 0: $14730 \mathrm{kWh}$

$\left.\begin{array}{|l|l|l|l|l}€ 60.000 \\ \epsilon 50.000 \\ \epsilon 40.000 \\ \epsilon 30.000 \\ \epsilon 20.000 \\ \epsilon 10.000 \\ \epsilon 0 \\ -\epsilon 10.000 \\ -\epsilon 20.000 \\ -€ 30.000 \\ -€ 40.000 \\ -\epsilon 50.000\end{array}\right]$

Fig. 1. Cumulative cash flow - Case 1: $10 \mathrm{~kW}$ Not integrated-Other PV system.

Second case: $10 \mathrm{~kW}$ PV system

Classification according to DM 19/02/07: Partially integrated - FIT Value: $0.404 € / \mathrm{kWh}$ Classification according to DM 06/08/10: PV in buildings - FIT Value: $0.360 € / \mathrm{kWh}$ Initial investment cost: $45000 €$ - Yearly production at year $0: 14730 \mathrm{kWh}$

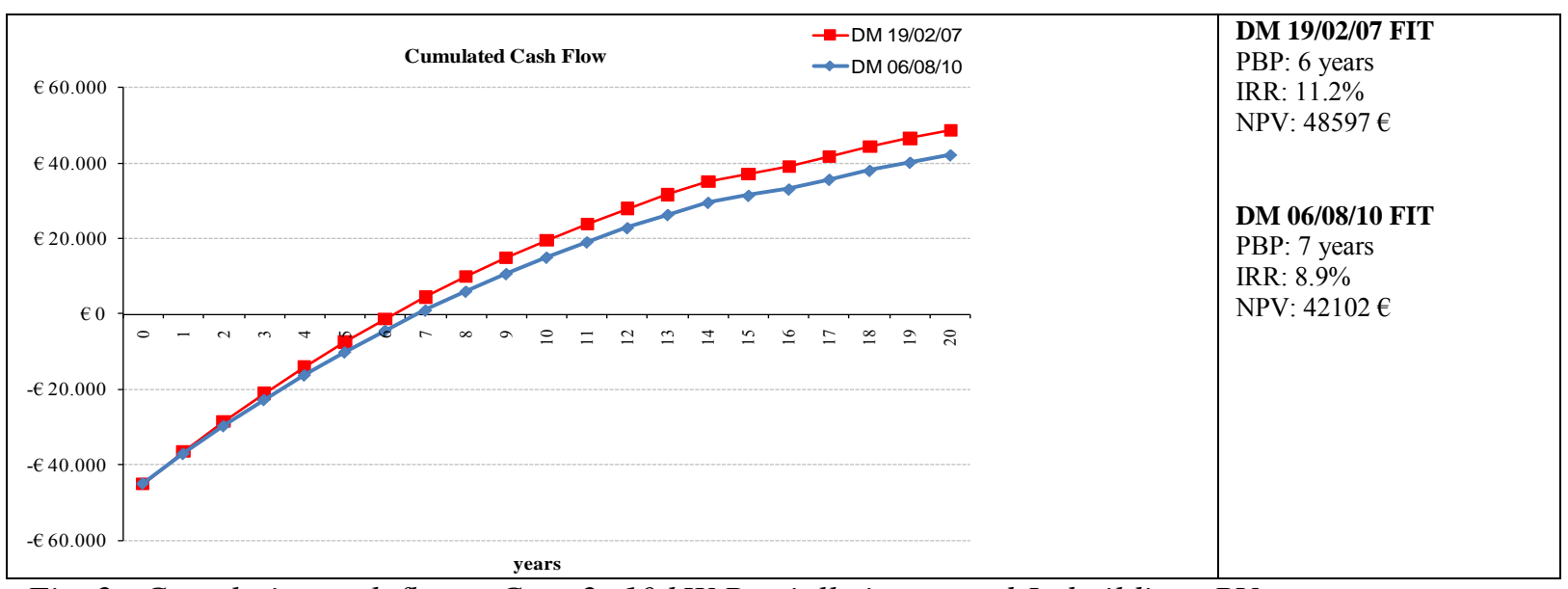

Fig. 2. Cumulative cash flow - Case 2: $10 \mathrm{~kW}$ Partially integrated-In buildings PV system. 
Third case: $10 \mathrm{~kW}$ PV system

Classification according to DM 19/02/07: Totally integrated - FIT Value: $0.442 € / \mathrm{kWh}$ Classification according to DM 06/08/10: PV in buildings - FIT Value: $0.360 € / \mathrm{kWh}$ Initial investment cost: $45000 €-$ Yearly production at year $0: 14730 \mathrm{kWh}$

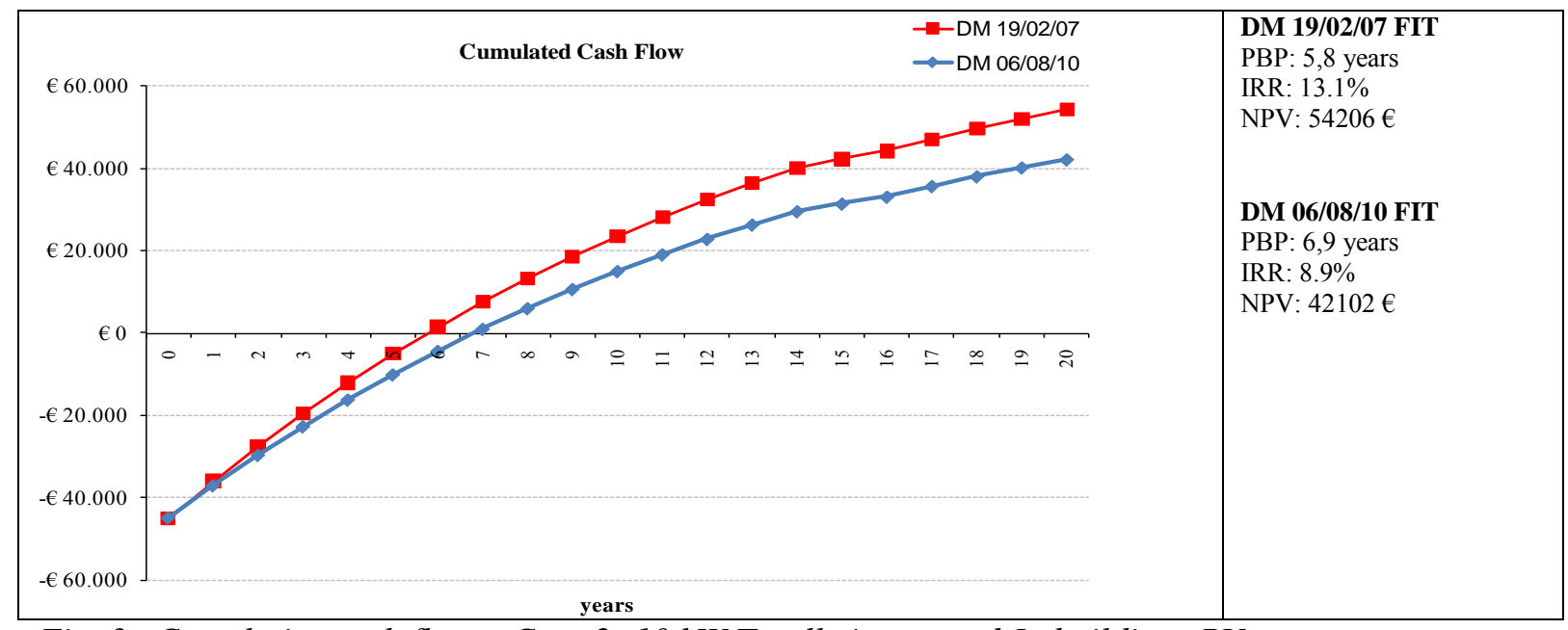

Fig. 3. Cumulative cash flow - Case 2: $10 \mathrm{~kW}$ Totally integrated-In buildings PV system.

Fourth case: $250 \mathrm{~kW}$ PV system

Classification according to DM 19/02/07: Not integrated - FIT Value: $0.346 € / \mathrm{kWh}$

Classification according to DM 06/08/10: Other PVs - FIT Value: $0.303 € / \mathrm{kWh}$

Initial investment cost: $1000000 €$ - Yearly production at year $0: 268250 \mathrm{kWh}$

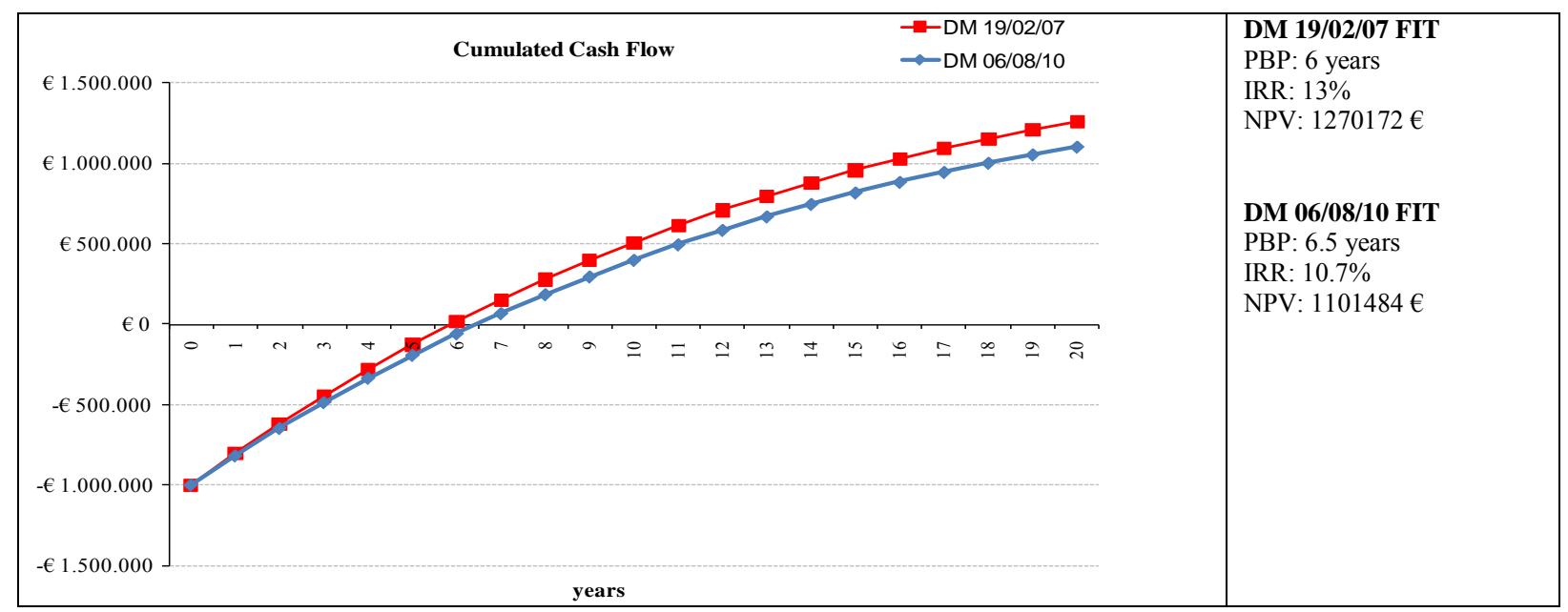

Fig. 4. Cumulative cash flow - Case 1: $250 \mathrm{~kW}$ Not integrated-Other PV system.

Fifth case: $250 \mathrm{~kW}$ PV system

Classification according to DM 19/02/07: Partially integrated - FIT Value: $0.384 € / \mathrm{kWh}$ Classification according to DM 06/08/10: PV in buildings - FIT Value: $0.335 € / \mathrm{kWh}$ Initial investment cost: $1000000 €$ - Yearly production at year $0: 268250 \mathrm{kWh}$ 


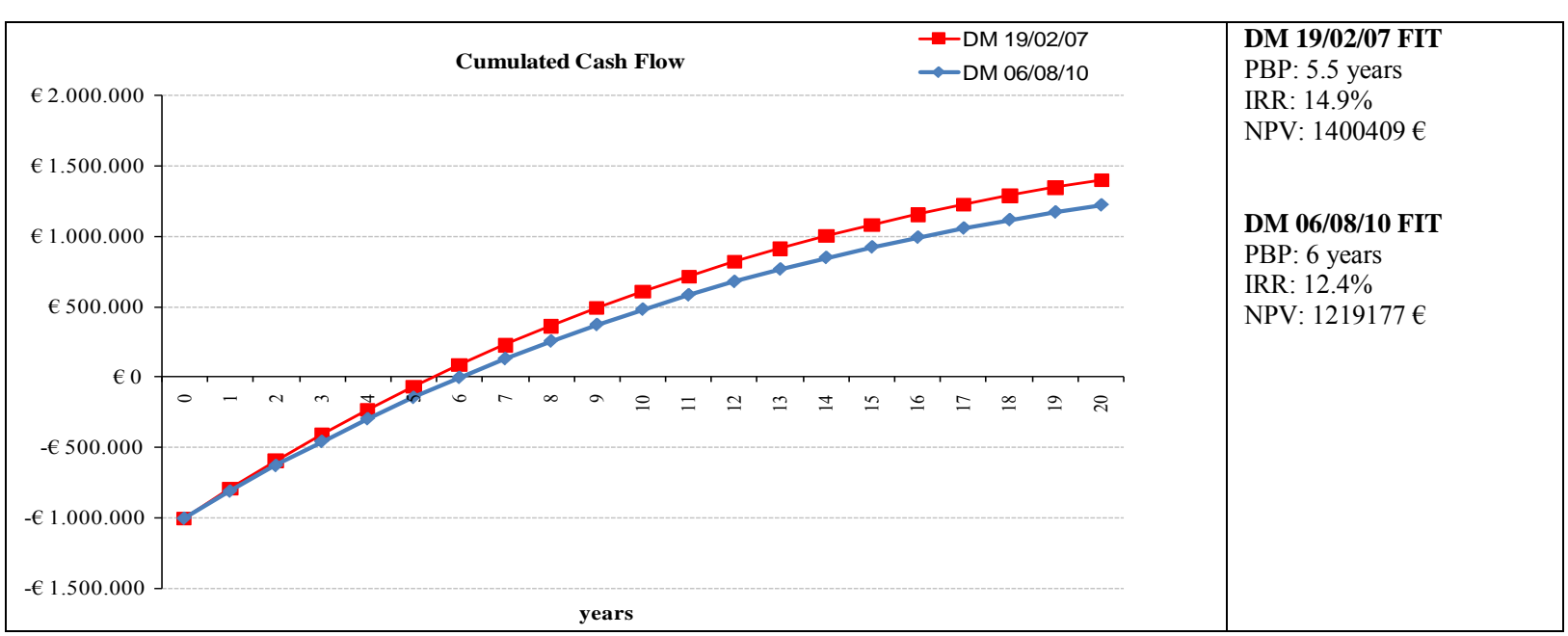

Fig. 5. Cumulative cash flow - Case 2: $250 \mathrm{~kW}$ Partially integrated-In buildings PV system.

Sixth case: $250 \mathrm{~kW}$ PV system

Classification according to DM 19/02/07: Totally integrated - FIT Value: $0.422 € / \mathrm{kWh}$ Classification according to DM 06/08/10: PV in buildings - FIT Value: $0.335 € / \mathrm{kWh}$ Initial investment cost: $1000000 €-$ Yearly production at year $0: 268250 \mathrm{kWh}$

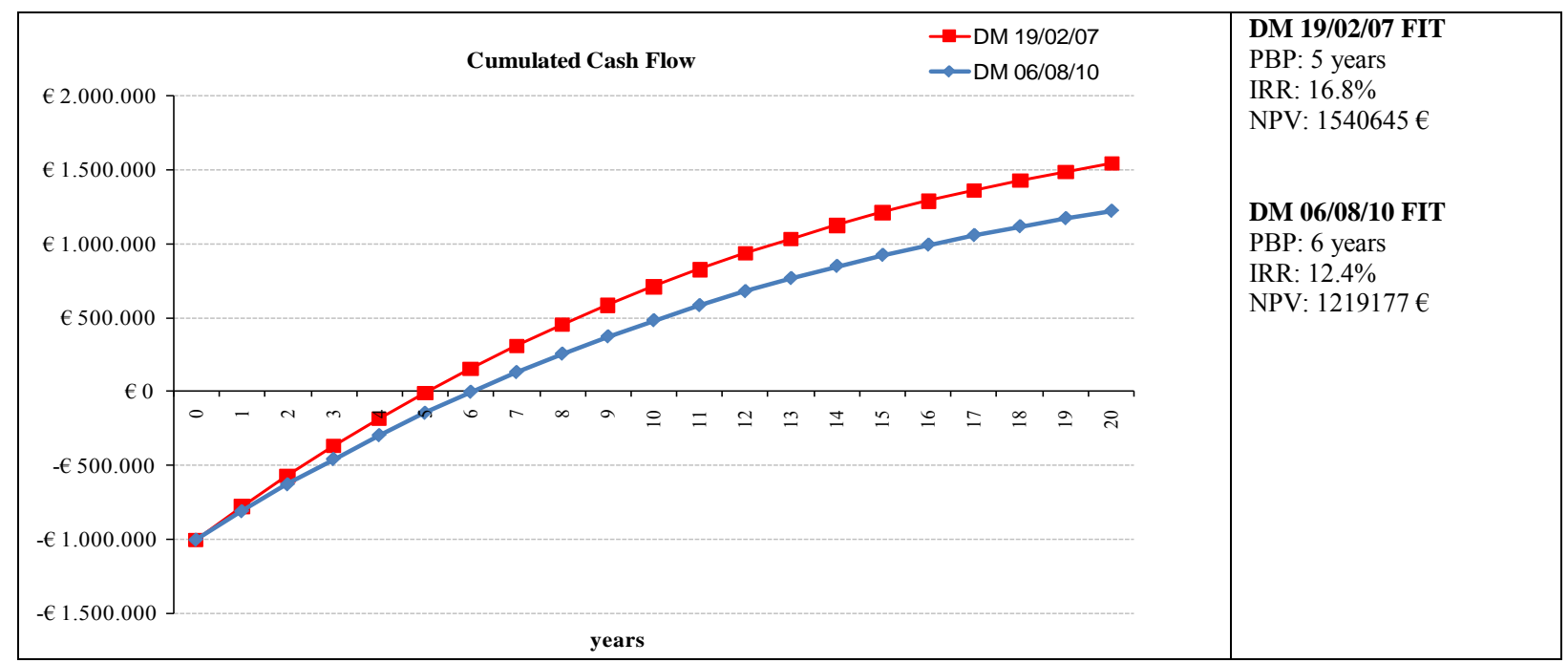

Fig. 6. Cumulative cash flow - Case 2: $250 \mathrm{~kW}$ Totally integrated-In buildings PV system.

\section{Discussion and Conclusions}

Simulations show that in the transition from the DM 19/02/07 to the DM 06/08/10:

- PBP increases and IRR and the NPV indexes decreases of about one year in all cases;

- The most significant variations are in the case of Totally integrated PV systems that, with the new Decree, are considered PV systems in building as the major part of Partially integrated PV Systems;

- The differences between economical indexes evaluated are higher for PV systems with lower rated power.

This last consideration, together with the fact that the new FITs have been decreased mainly for totally integrated PV systems, puts into evidence that the new Decree significantly penalizes the architectural PV integration. 
This items represents a strongly criticism of the new incentive policy, because it seems to not adequately promote the reduction of the visual impact of PV systems with traditional components.

Really, the new Decree also considers, as above mentioned, PV systems with innovative components for total building integration, for which higher FITs values are established; in the present work these PV typologies have not been analyzed due to the fact that precise indications for their characterization are still lacking. A possibility of improvement, leading to higher incentives for building integrated PV system, can come from the definition of these characteristics, operated so as to include the higher number of situations of architectural integration accepted by the DM 19/02/07.

\section{References}

[1] European Council, Directive 2001/77/EC of the Council on the promotion of electricity produced from renewable energy sources in the internal electricity market, 2001.

[2] Kyoto Protocol to the United Nations Framework Convention on Climate Change, 1997.

[3] European Council, Directive 2009/28/EC April 23, 2009.

[4] Nomisma Energia, Le nuove fonti rinnovabili per l'energia elettrica in Europa, Arti Grafiche Tilligraf Srl, 2007.

[5] A. Campoccia, L. Dusonchet, E. Telaretti, G. Zizzo, Comparative analysis of different supporting measures for the production of electrical energy by solar PV and Wind systems: Four representative European cases, Solar Energy Vol. 83 Issue 3, 2009, pp. 287-297.

[6] Italian Ministry for Productive Activities Decree, Criteri per l'incentivazione della produzione di energia elettrica mediante conversione fotovoltaica della fonte solare (D.M. 28/06/2005), 2005.

[7] Italian Ministry for Economical Development Decree, Criteri e modalità per incentivare la produzione di energia elettrica mediante conversione fotovoltaica della fonte solare in attuazione dell'articolo 7 de 1 decreto legislativo 29 di cembre 2003 n. 387 ( D.M. 19/02/2007), 2007.

[8] Italian Ministry for Economical Development Decree, Incentivazione della produzione di energia elettrica mediante conversione fotovoltaica della fonte solare (D.M. 06/08/2010), 2010 .

[9] B. J. Feibel, Investment Performance Measurement. Wiley Interscience, 2003. 